\title{
AS POLÍTICAS PÚBLICAS DE CULTURA E AS ARTES NO CEARÁ: a criação e consolidação do centro de artes visuais - Casa Raimundo Cela
}

\author{
Anderson de Sousa Silva*
}

RESUMO: Este artigo tem por objetivo discorrer sobre a criação e a trajetória do Centro de Artes Visuais - Casa Raimundo Cela e do Salão Nacional de Artes Plásticas do Ceará, enquanto mecanismos de afirmação de uma política pública das artes no Ceará. Tem-se como foco refletir sobre a relação entre Estado e cultura, que em meados dos anos 1960 se intensificou, devido à criação da Secretaria e do Conselho Estadual de Cultura, assim como a atuação de artistas e intelectuais nos órgãos vinculados a estas instituições. O estudo em questão também se propõe a investigar o projeto de inserção do Ceará no panorama artístico brasileiro, por meio da criação de um Salão de Arte Nacional, da emergência de uma nova geração de artistas e de novas figurações estéticas surgidas no campo artístico local por meio do diálogo com o nacional.

PALAVRAS-CHAVE: Artes Plásticas; Casa Raimundo Cela; Política Cultural.

\section{Public politcs of culture and the arts in Ceará: creation and consolidation of the center for visual arts- Casa Raimundo Cela}

\begin{abstract}
This article aims to discuss the creation and history of the Center for Visual Arts: Casa Raimundo Cela and the National Plastic Arts of Ceara Hall, as an affirmation mechanism of public politics culture and to official institutions of the arts in Ceara. It has been focused on reflecting in the relationship between the State and culture, which in the mid-1960s has intensified due to the creation of the Secretaria and the State Council of Culture, as well as the performance of artists and intellectuals in the organs linked to these institutions. In the meantime, the present study also aims to investigate the Ceara insertion project in the Brazilian art scene, through the creation of a Hall of National Art, either the emergence of a new generation of artists and new aesthetic figurations emerged in the local and national artistic dialogues.
\end{abstract}

KEYWORDS: Visual Arts; Arts Center Raimundo Cela; Cultural Politcs.

\section{Las políticas públicas de cultura e las artes en Ceará: la creación e la consolidación del centro de las artes visuales - Casa Raimundo Cela}

RESUMEN: Este artículo tiene como objetivo discutir la creación y la historia del Centro de Artes Visuales - Casa Raimundo Cela y el Salón Nacional de Artes Plásticas de Ceará, como mecanismos de afirmación de una política pública de formalización de las instituciones de arte en Ceará. Se ha centrado en la reflexión sobre la relación entre Estado y cultura, que a mediados de la década de 1960 se ha intensificado debido a la creación de la Secretaría y el Consejo de Estado de Cultura, así como el trabajo de los artistas e intelectuales en los órganos vinculados a estas instituciones. El artículo también tiene como objetivo investigar el proyecto de inserción de Ceará en la escena del arte brasileño, a través de la creación de un Salão de Arte Nacional, del surgimiento de una nueva generación de artistas y de nuevas figuraciones estéticas que aparecieron en el campo artístico local por intermedio del diálogo con el escenario nacional.

PALABRAS-CLAVE: Artes Plásticas; Casa Raimundo Cela; Política Cultural.

\footnotetext{
*Doutorando em História pela Universidade Federal de Pernambuco (UFPE). Mestre em História Social pela Universidade Federal do Ceará (UFC). Email: andersonsousa87@ gmail.com
} 


\section{O conselho estadual de cultura e o centro de artes visuais - Casa Raimundo Cela}

A criação do Conselho Estadual de Cultura, entre os anos de 1966 e 1967, sob a presidência do então secretário de cultura Raimundo Girão, marcou uma nova etapa no processo de criação de políticas públicas culturais no Ceará. Alguns indivíduos, ligados aos grupos de intelectuais das letras e das artes, passaram a exercer cargos públicos de gestão cultural. A ideia da criação do Conselho não era tão recente. No início dos anos 1960, já havia uma forte articulação em prol da criação e regulamentação de uma instituição consultiva para os assuntos da cultura. Por problemas estruturais e técnicos, porém, o conselho não entrou em funcionamento ${ }^{1}$. Em 1963, houve uma nova tentativa de dá início às atividades da instituição. Todavia, foi com a criação da Secretaria de Cultura do Ceará, em 1966, no governo de Plácido Aderaldo Castelo, que oficialmente foi inaugurado o Conselho Estadual de Cultura.

O escritor Otacílio Colares além de liderar o Serviço de Difusão Cultural do Estado, foi nomeado como conselheiro da área de cinema e passou a ser um dos redatores da Aspectos, revista oficial, publicada quadrimestralmente, pela Secretaria e pelo Conselho de Cultura estaduais, no qual teve por finalidade publicizar a programação, trabalhos, ideias e atividades culturais patrocinadas pelo Estado. Além de Otacílio Colares, outros intelectuais se envolveram com o Conselho, entre os quais: o escritor Braga Montenegro, que foi nomeado responsável pelo setor de Literatura; Manuel Eduardo Pinheiro Campos e Nadir Pápi de Sabóia no setor de Artes de Movimento; Orlando Vieira Leite e Wanda Ribeiro Costa no setor de Música; já a artista Heloysa Juaçaba ficou à frente da área de Artes Plásticas e o escritor Antônio Girão Barroso foi nomeado suplente ${ }^{2}$.

O então secretário municipal de educação e cultura, Ernando Uchoa, construiu sua trajetória como gestor cultural, sendo nomeado, a partir de 1971, como sucessor de Raimundo Girão na Secretaria de Cultura do Estado e, consequentemente, tornando-se presidente do Conselho Estadual de Cultura no mesmo período. Com relação às ações planejadas e desenvolvidas pelo setor de Artes Plásticas do Conselho, compete observar a respeito da criação do Centro de Artes Visuais - Casa Raimundo Cela.

O Centro de Artes Visuais, hoje Casa de Cultura Raimundo Cela, foi fundada com a intenção de haver um espaço para todas as manifestações artísticas que trafegam e no momento transcendem o que se convencionou chamar Artes Plásticas. Contamos com grandes colaboradores, como nosso amigo baiano (meu e de Haroldo) Clarival do Prado Valadares, médico, escritor, poeta, historiador e crítico de arte, que elaborou a programação inicial da casa. Essa programação enfatizava a realização de cursos para jovens iniciantes no aprendizado da arte, palestras realizadas por artistas 
e críticos de arte vindo de outros estados e exposições. Alguns dos artistas e críticos de arte que aceitaram o convite do Prof. Raimundo Girão, Secretario de Cultura, foram: Clarival do Prado Valadares, José Roberto Teixeira Leite, Jacob Klintowitz, Walter Zanine, Roberto Pontual, Frederico de Moraes, Olívio Tavares de Araújo, três vezes, Valmir Ayala, Goebel Weyne (...). Desta maneira a Casa Raimundo Cela ajudou os artistas que tentavam a busca de suas identidades profissionais. A comercialização da obra de arte nesse período coincidiu com grandes transformações sociais e culturais que ocorriam em nosso país e no mundo (...). Nosso objetivo era esclarecer as pessoas e organizar exposições para que elas vissem que estava surgindo no Ceará uma nova geração de artistas, capazes de construir uma arte comprometida, e até mesmo ousada no seu tempo. (...) A Casa Raimundo Cela realizou nove "Salão de Artes Plásticas", e vale recordar que o primeiro Salão realizado no Colégio Militar de Fortaleza foi feito um catálogo especial, em homenagem ao Antônio Bandeira ${ }^{3}$.

De acordo com o depoimento de Heloísa Juaçaba percebe-se que a criação da Casa Raimundo Cela fez parte de um investimento da Secretaria de Cultura para ampliar os espaços para as manifestações artísticas no Ceará. O diferencial da instituição foi a vinda de artistas e críticos de arte de outros polos do país, com a finalidade de elaborar um programa de atividades para a Casa. O crítico de arte Clarival do Prado Valadares elaborou, junto a Heloísa Juaçaba, o Plano Diretor ${ }^{4}$ da instituição, que previa a realização de cursos, conferências e exposições, e dentre as quais um Salão Nacional de Arte. É notório o desejo de Juaçaba em dar visibilidade à produção de uma nova geração de artistas, que surgiu nesse período, e propiciar a estes o contato com o que se pensava sobre arte no Brasil. O surgimento do Salão Nacional, certamente, tivera o propósito de fomentar o diálogo entre a produção artística cearense e a brasileira.

Nessa conjuntura, uma exposição, de considerável importância, realizada pela Casa Raimundo Cela, no ano de 1969, foi a mostra das obras, de 28 artistas, que faziam parte do acervo do Museu de Arte Contemporânea da USP, sob a orientação do então diretor do MAC/USP, Walter Zanini. Segundo as palavras de Otacílio Colares, que estava à frente do Departamento de Difusão da Cultura, a mostra:

Trata-se de uma oportunidade excepcional que se oferece aos amantes das artes plásticas, de apreciar, na variedade das técnicas, na predominante ousadia das concepções, todo um repertório de valores novos que surgem em nosso país, estimulados esses valores pelo aplauso e a compreensão das elites mais significativas ${ }^{5}$.

Este trecho, do catálogo da exposição das obras dos 28 artistas do acervo MAC/USP, tem um forte teor político e ideológico, principalmente ao reconhecer a importância da participação das elites quanto ao reconhecimento e entendimento de tais iniciativas. Uma das principais questões a serem abordadas, contudo, é a influência e repercussão que essa mostra de arte exerceu no campo artístico local, justamente por se tratar da produção de novos 
artistas, permeada por renovadas concepções de artes. Interessante pensar em Walter Zanini, enquanto crítico e gestor de arte, que exerceu certa autoridade em assuntos atinentes ao movimento de arte no Brasil. Zanini chegou a se reunir com o Conselho Estadual de Cultura, para debater, junto aos conselheiros, novas políticas e rumos para o circuito artístico no Ceará ${ }^{6}$. Nesse sentido, é pertinente o debate acerca da intervenção do Estado na vida artística do Ceará.

Instituindo a Secretaria de Cultura, pioneira em todo o Brasil, a administração Plácido Castelo deu dimensões novas à atividade artístico - intelectual na terra cearense.

O referido organismo, com poucos meses de sua implantação, já deu mostras da amplitude da sua mensagem, que é a de fazer assistidas pelo Estado todas as iniciativas de cunho cultural.

Prova eloquente da afirmativa é a instituição da Exposição coletiva que hora se inaugura na "Casa de Raimundo Cela", órgão vinculado à citada Secretaria, através do Departamento de Difusão da Cultura.

A partir de agora, Arte e Governo estão de mãos dadas, numa obra que há de assegurar ao Ceará grandes glórias no futuro ${ }^{7}$.

A apropriação do campo artístico do Ceará, pelo governo estadual, reflete uma postura política não apenas local, mas nacional. As relações entre arte e Estado, principalmente em governos militares, são acentuadas como uma busca por legitimação e reestruturação do campo cultural. De acordo com Israel Oliveira: "tanta movimentação política em um período dito de declínio nos leva a crer que o Governo Militar não estava disposto a abrir mão do controle dos espaços culturais ${ }^{8}$ ". Percebemos esse esforço de controle, por parte do Estado, por meio das aproximações entre os órgãos federais de cultura e os estaduais. A Casa Raimundo Cela também está inserida nesta conjuntura. Em entrevista, concedida ao pesquisador Alexandre Barbalho, Heloísa Juaçaba destaca que o convite feito ao crítico de arte Clarival do Padro Valadares, para a elaboração do plano diretor da Raimundo Cela, se deu pelo fato de Valadares ser o responsável pela área de artes no Conselho Federal de Cultural. Com isso, Juaçaba pretendia que a Raimundo Cela tivesse um formato que valorizasse a arte e os artistas locais, mas que esse formato já fosse conhecido e usado por boa parte do Brasil ${ }^{9}$.

Nesse momento, convém abrir um parêntese para destacar a trajetória de Heloísa Juaçaba enquanto gestora das artes, não apenas por ter sido idealizadora da Casa Raimundo Cela, mas por sua atuação nas instituições oficiais de cultura do Ceará, tendo sido: diretora do Departamento Municipal de Cultura, durante a gestão do prefeito José Walter Cavalcante (1967-1970); ficou à frente, por mais de uma década, do setor de Artes Plásticas do Conselho Estadual de Cultura; e tomou parte de várias comissões de organização e júri do Salão de 
Abril, entre o final dos anos 1960 e início dos $1970^{10}$. Juaçaba também teve suma importância para a consagração de uma nova geração de artistas, principalmente aqueles que figuravam na Casa Raimundo Cela, que por sua vez, influenciou a formação de um mercado de arte no Ceará.

Em 1976, o crítico e jornalista Eliezer Rodrigues escreve um artigo comentando que a conjuntura favorável à criação de galerias no Ceará começou com a Raimundo Cela, com o auxílio de Heloísa Juaçaba que, em seu trânsito na alta sociedade cearense, vem atraindo consumidores de arte, principalmente para os artistas ligados à Secretaria de Cultura. Juaçaba exerce, dessa forma, um poder de consagração junto aos artistas da Raimundo Cela ${ }^{11}$.

Como o trecho informa, Juaçaba foi uma mulher das elites, sua fluída circulação nos meios políticos, econômicos e da alta sociedade cearense, a levou a emprestar seu capital simbólico, no que diz respeito a divulgação e venda das obras dos artistas, potencializando um mercado de arte ainda embrionário. Jean François Sirinelli destaca a atuação das elites culturais no campo da arte e da cultura. Primeiramente, o autor faz uma diferenciação entre criadores e mediadores culturais, sendo os primeiros os responsáveis pela criação artística e os últimos, aqueles que contribuem, com seu poder de influência, para difundir o trabalho dos criadores. Muitas vezes, esses mediadores se tornam uma elite cultural com fortes relações com os poderes públicos locais ${ }^{12}$.

A partir das ponderações de Sirinelli, analisamos o lugar de Heloisa Juaçaba como uma mediadora que passou a tomar parte de uma elite cultural de Fortaleza, fazendo uso dos acessos aos meios do poder, tanto econômicos quanto políticos, para dar visibilidade a produção dos artistas da Casa Raimundo Cela.

\section{O Salão Nacional de Artes Plásticas do Ceará}

Em meio a esse contexto, de idealização de instituições para a formação de novos artistas cearenses e de uma forte intensificação das políticas públicas de cultura, surgiu à primeira edição do Salão Nacional de Artes Plásticas do Ceará.

Expedimos cartas para todas as secretarias de cultura do Brasil. O Rio de Janeiro participou em peso, seus melhores gravadores compareceram ao Salão. Tivemos representes do Amazonas, Acre, Paraíba, de todos os estados do Brasil vieram quadros. Eram caixas e mais caixas chegando (...). Quando nós abrimos os olhos eu disse: dona Heloysa onde é que nós vamos fazer esse Salão? Aqui ele não cabe. E ela: Pronto, Félix, o que é que nós vamos fazer? Eu disse-lhe: Só tem um lugar, o Colégio Militar, que parece que é grande e tem aquelas salas cumpridas, imensas. Fomos até o comandante, ele achou a ideia maravilhosa e cedeu o prédio do Colégio Militar; onde aconteceu o primeiro Salão Nacional de Artes Plásticas do Ceará, em 
1967. (...) Outra dificuldade: convidar os críticos de fora para os trabalhos de julgamento e premiação. Decidiu-se pelos nomes de Clarival do Prado Valadares, José Roberto Teixeira Leite; este um dos maiores críticos do Rio de Janeiro, que dividiram os trabalhos com dois representantes locais (...). Este Salão ficou um mês em exposição, com uma segurança total de soldados, exigindo documentação dos visitantes. Foi uma boa divulgação da Secretaria de Cultura do Ceará e os seus artistas. Clarival me convidou para expor no Rio de Janeiro, na Galeria Goeldi, uma galeria muito conceituada que ele dirigia, na Rua General Osório, em Ipanema. Por seu intermédio, eu fui expor pela primeira vez no Rio de Janeiro. Ele convidou outros artistas também. Clarival editava nesta galeria os "Cadernos Brasileiros". Por conta desta publicação a galeria foi fechada pelos militares, durante a revolução ${ }^{13}$.

Este fragmento, de uma entrevista concedida pelo artista Tarcísio Félix a Dodora Guimarães, evidencia o empenho em divulgar a primeira edição do certame para os outros estados do país, através do envio das cartas para as respectivas secretarias de cada estado. É importante atentar para a vinda de renomados críticos de arte para compor a comissão de julgamento e premiação dos trabalhos expostos, pois, a partir disso, identificamos uma rede de relações tecidas em torno do Salão Nacional. Clarival do Prado Valadares, por exemplo, conheceu o trabalho dos artistas cearenses e convidou alguns destes para expor na galeria em que assumia o cargo de diretor no Rio de Janeiro, provavelmente uma experiência que possibilitou a ampliação da atuação desses indivíduos no circuito artístico brasileiro. É pertinente pesquisar os posicionamentos políticos desses críticos de arte, levando em consideração que a galeria de Clarival do Prado foi fechada, no período da Ditadura Militar, devido as suas publicações. Este acontecimento nos conduz a pensar no papel do crítico de arte ao tomar parte como membro de uma comissão de júri de um Salão de Artes promovido por um governo vinculado a um regime ditatorial. Os representantes locais da comissão de júri do $1^{\circ}$ Salão Nacional do Ceará foram: Otacílio Colares, Mário Barata e Antônio Girão Barroso $^{14}$.

Convém refletir sobre os espaços artísticos e suas imbricações com os contextos político e social de um determinado período. Neste caso, trata-se de 1960 a 1980, em que o Brasil viveu a Ditadura Militar. Para Renato Ortiz, o pós-1964 provocou transformações no Brasil não apenas em sua esfera política, mas também na econômica e cultural. Ortiz realça que houve um considerável desenvolvimento econômico no país, que provocou a consolidação de um mercado de bens materiais, e de forma correlata, o desenvolvimento de um mercado de bens culturais amparados por políticas governamentais ${ }^{15}$. A partir dessa perspectiva, pensamos nas instituições artísticas do Ceará como sendo integrante dessa dinâmica de apropriação, por parte do Estado, do campo cultural. 
Aí está o $1^{\circ}$ Salão Nacional de Artes Plásticas do Ceará. É uma iniciativa sem dúvida arrojada, que requereu muita canseira, exigiu grande dose de idealismo e capacidade de realização dos seus organizadores (...). A Secretaria de Cultura do Estado do Ceará, pelo Departamento de Difusão da Cultura, ao qual está vinculada a "Casa de Raimundo Cela", promotora da mostra, pode dar-se por satisfeita com o êxito da empreitada. Ao primeiro Salão ocorreram artistas de todas as tendências, de todos os gêneros de realização pictórica, numa distribuição de pujança latente, à qual faltava tão somente o estímulo tão necessário. Poderemos dizer que, não fora a existência da Secretaria de Cultura, não seria possível uma realização de tal porte, reunindo mais de duas centenas de obras de autores cearenses, de diversos Estados da Federação e até mesmo do exterior. As artes não prescindiram jamais do Poder Público (...). O Governador do Estado, dr. Plácido Aderaldo Castelo, o Secretario de Cultura, professor Raimundo Girão, e os responsáveis pela realização do $1^{\circ}$ Salão Nacional de Artes Plásticas agradecem, em nome dos artistas cearenses, a todos aqueles que de outras unidades do país mandaram a sua nota ponderável e valiosa de presença ${ }^{16}$.

Os trechos do catálogo do $1^{\circ}$ Salão Nacional do Ceará evidencia a participação do Governo Estadual, por meio da Secretaria de Cultura, na organização do certame. As personalidades políticas do período, tais como o governador e o secretario de cultura, são mencionados como aqueles que exercem a função de estar à frente dos assuntos de interesse do Estado. O setor cultural passa a ser visto como uma área estratégica para receber investimentos, e, consequentemente, a criação de um Salão Nacional serviu como um meio de destacar, para outras regiões do Brasil, as políticas em prol do desenvolvimento artístico no Ceará. Entre o final dos anos 1960 e início dos 1970 foi crescente a criação de novos Salões e exposições de artes, promovidos por órgãos estaduais e municipais, entre os quais pode ser ressaltado: o Salão dos Novos ${ }^{17}$ patrocinado pelo Departamento de Turismo da Prefeitura; Exposição de Arte Infantil ${ }^{18}$ também promovida pelo Departamento de Turismo da Prefeitura, e destinada aos alunos da rede municipal de ensino; Salão de Arte Fotográfica ${ }^{19}$ organizado pelos alunos do curso de Fotografia do Cinema de Arte Universitário (C.A.U); além do já legitimado Salão de Abril, apropriado pela Prefeitura de Fortaleza desde $1964 .{ }^{20}$ A presença de autoridades políticas na abertura dessas mostras reforça a ideia de uma política de artes "amparada" pelo Estado.

Com a presença do governador César Cals e inúmeras autoridades culturais do Estado, artistas cearenses e de outros Estados, foi aberto ontem às 20h30min, na Casa Raimundo Cela, o Salão Nacional de Artes Plásticas, promovido pela Secretaria de Cultura e Promoção Social, sob a coordenação da sra. Heloysa Juaçaba.

O Salão reuniu mais de 40 trabalhos, tendo sido selecionados 79 obras que receberam a consideração especial do crítico de arte Olívio Tavares da Editora Abril. Aos melhores trabalhos, a Secretaria de Cultura ofereceu prêmios que variam de 4 a 2 mil cruzeiros ${ }^{21}$. 
A manchete do trecho da matéria, acima transcrita, destacou a presença do governador na abertura da exposição: "Governador na abertura do Salão Nacional de Artes Plásticas". Cabe pensar sobre os múltiplos usos da imprensa, inclusive servir como veículo de divulgação dos feitos do Estado. Percebe-se que com um título desses, a ideia não era apenas informar sobre a abertura do Salão, mas principalmente mencionar, de forma valorizada, a presença do governador César Cals e das chamadas autoridades da cultura. A participação dos artistas do Ceará e de outros estados, assim como a premiação deles, fazia parte de um programa de governo. Nessa conjuntura, interessa investigar os efeitos da participação direta do Estado na vida artística do Ceará.

O historiador francês Phillipe Urfalino nos auxilia a pensar e a historicizar o conceito de política cultural através de suas análises acerca da história das políticas culturais e, como em diferentes temporalidades, as autoridades públicas fizeram uso desse recurso para intervir nas trajetórias dos diversos grupos sociais. Urfalino atenta que é importante ter cuidado para não reduzir e simplificar a definição de política cultural, mas sim entendê-la como fazendo parte de um conjunto de ideias e valores representativos para cada Estado em seus contextos intelectuais e políticos ${ }^{22}$. Segundo as considerações do autor, para que a noção de política cultural seja trabalhada de forma adequada, é importante levar em consideração o debate intelectual, que de certa forma, legitima ou se atrita às ações públicas. É preciso perceber as especificidades de cada temporalidade. Desse modo, as ações da política cultural no Brasil durante o Estado Novo, por exemplo, são de matrizes diferentes das diretrizes traçadas na Ditadura Militar. No Estado Novo, a ideia de nacionalismo foi o elemento norteador das políticas culturais; já na Ditadura Militar, a noção desenvolvimentista do capitalismo foi o mote condutor para uma intensificação da produção dos bens culturais ${ }^{23}$.

Nesse aspecto, porém, o desenvolvimento das artes se tornou um empreendimento não só para o governo, pois o surgimento das galerias particulares também movimentou o circuito artístico local, resultando na emergência de um mercado de arte. No ano de 1967, já tem-se notícia sobre exposições dos artistas Descartes Gadelha, Heloísa Juaçaba e Estrigas na Galeria Pedro Jorge ${ }^{24}$. A Galeria do Ideal Clube, através de seu Departamento de Cultura promoveu diversas exposições de artes plásticas ${ }^{25}$ e a Galeria Recanto de Ouro Preto ${ }^{26}$, de Ignez Fiúza, também figurou nesse cenário, potencializando a circulação e comercialização da produção artística do Ceará e de outras localidades do Brasil, pois artistas de outros estados eram convidados a realizar exposições. Uma questão importante de ser analisada são as possíveis 
aproximações e distanciamentos entre os espaços artísticos institucionalizados e um mercado comercial de arte, em crescimento, por meio das galerias.

Retornando ao catálogo do $1^{\circ}$ Salão Nacional do Ceará, percebe-se a proposta em abranger todos os gêneros artísticos, desde pintura, desenho e escultura até os mais recentes. Na quarta edição do Salão Nacional do Ceará, em 1973, além dos gêneros supracitados, houve a inserção da categoria "pesquisas artísticas"27, uma modalidade nova para dar conta dos trabalhos que não se enquadravam nas outras técnicas e estéticas. O movimento de aglutinar as diferentes tendências ocorreu no plano nacional também. Com a criação da FUNARTE, nos anos 1970, o Salão Nacional de Arte Moderna se funde ao Salão Nacional de Belas Artes, passando a ser chamado de Salão Nacional de Artes Plásticas, com a ideia de que antigos e novos valores artísticos poderiam conviver, apresentando, dessa forma, um panorama da arte brasileira ${ }^{28}$.

Com relação às novas modalidades artísticas, no âmbito do Salão, é importante discutir sobre os novos modos de pensar e produzir arte, surgidos no período em questão. Entre o final dos anos 1960 e início dos 1970, a Arte Conceitual ganhou força no cenário nacional. A Arte Conceitual teve, como uma de suas principais características, a função de problematizar a própria concepção de arte e seus sistemas de produção e legitimação ${ }^{29}$. As "pesquisas artísticas" provavelmente dialogaram com esse novo entendimento de arte. Os artistas passaram a questionar seus métodos de criação, dando mais destaque, talvez, as ideias e aos conceitos impressos nas obras. Ou seja, o artista se assumiu enquanto um pesquisador e problematizador do sistema de arte vigente. E, provavelmente, isso tenha se reverberado também na recepção, circulação e crítica de artes.

O historiador da arte Paulo Reis, analisa a arte de vanguarda, no Brasil, na década de 1960. Ao discorrer sobre a exposição "Nova objetividade brasileira", de 1967, realizada no Museu de Arte Moderna do Rio de Janeiro, ressalta para a não definição de algumas obras nas modalidades tradicionais (pintura, desenho, escultura), sendo que parte desses trabalhos receberam a denominação de "objeto". ${ }^{30}$ Ao consultarmos o catálogo do Salão Nacional do Ceará da quinta edição, em 1976, identificamos uma modalidade artística denominada "outras técnicas". Nesta modalidade, expuseram artistas com as técnicas: talha, montagem, xilogravura, gravura, gravura, colagem e objeto. Ao que tudo indica, todos os trabalhos que não enquadravam nas linguagens de pintura, desenho e escultura, foram expostos em "outras técnicas". Os artistas José Francisco Pinheiro de Souza (J. Pinheiro) e Zé Pinto tiveram suas técnicas de trabalho chamadas de "objeto". Acreditamos que a presença dessas obras no Salão 
Nacional do Ceará de 1976 possa ser uma influência do que estava sendo produzido e discutido sobre arte no Brasil desde os anos 1960.

Com o passar dos anos, contudo, o Salão foi assumindo outros posicionamentos e critérios com relação a participação dos artistas. A edição de 1984, por exemplo, teve como principal proposta expor uma visão genuína da arte brasileira.

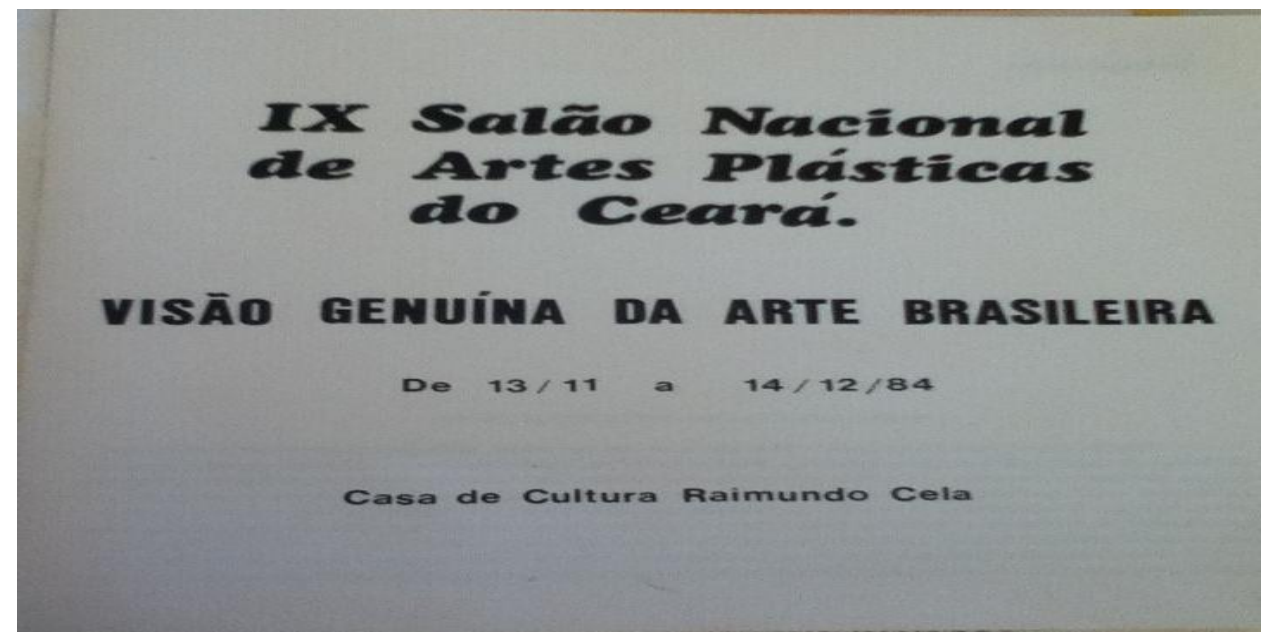

Figura 1 - Catálogo do IX Salão de Artes Plásticas do Ceará

O texto de apresentação do catálogo da nona edição do Salão Nacional do Ceará evidenciou que ideia da comissão de organização daquela edição era mostrar "na realidade atual, de uma arte brasileira com expressão artística distinta, apesar da dominação cultural que sofremos". A seleção dos trinta participantes, entre estes eruditos e populares, se baseou no critério da não filiação destes aos movimentos artísticos surgidos no exterior. Além disso, foram escolhidos dois artistas cearenses, com trabalhos mais inclinados para arte e cultura popular, para compor as salas especiais: Chico da Silva e Mestre Noza, sendo que este último nasceu em Pernambuco, mas se mudara para o Ceará ainda na infância.

Nesse sentido, o Salão também pode ser visto como um cenário de tradições e contradições. Percebemos, num primeiro momento, um esforço para reunir trabalhos relacionados com o circuito artístico nacional, que por sua vez, tinha conexão com a produção internacional; em seguida, o Salão se posiciona contrário a essas influências. Sabemos que no decorrer dos anos 1970, durante a gestão de Ernando Uchoa na Secretaria de Cultura do Ceará, "o popular passa a ter lugar de destaque, e disputa espaço com as políticas de promoção dos ambientes de engrandecimento da erudição (museus, bibliotecas, teatros e reedição de obras" ${ }^{31}$. Ainda segundo a pesquisa de Israel Oliveira, o popular passou a ser 
visto, pela ótica da política de cultura, como um elemento formador da identidade brasileira, por meio da articulação das múltiplas feições regionais atinentes ao Brasil. A partir desse ponto de vista, acreditamos que o fato do Salão Nacional de 1984 ter manifestado tais posturas, por seus organizadores, possa ser uma resposta a essa tendência vigente nas políticas de cultura do Ceará em privilegiar a produção artística popular e regional.

\section{O salão como lugar de disputa entre gerações?}

No âmbito do Salão Nacional do Ceará houve conflitos entre as antigas e novas gerações de artistas. Heloisa Juaçaba, enquanto diretora da Casa Raimundo Cela e organizadora do Salão Nacional do Ceará, foi uma das responsáveis pela emergência de jovens artistas, que estabeleceram uma linha de ruptura com as gerações passadas, principalmente com os artistas oriundos da Sociedade Cearense de Artes Plásticas (SCAP), que marcaram a história da arte cearense entre os anos 1940 e 1950. Esses jovens artistas foram conhecidos com a "Geração Dourada", entre os quais podem se destacar: Descartes Gadelha, Aderson Medeiros, Kleber Ventura, Sérgio Pinheiro, Roberto Galvão, Tarcísio Félix, Sergei de Castro, Bené Fonteles, entre outros ${ }^{32}$.

Lançando mão ao conceito de geração como instrumento de análise, percebemos que os novos usos e interpretações de tal noção, no campo historiográfico, têm ajudado no que se refere a compreender os processos geracionais. O sociólogo Karl Mannheim, frisa que o problema das gerações “é um dos guias indispensáveis à compreensão da estrutura dos movimentos sociais e intelectuais" ${ }^{\prime 33}$. O autor, porém, aponta alguns problemas com relação às gerações. Em primeiro lugar, é importante levar em consideração que nem sempre uma geração tem consciência de sua unidade, sendo que os vínculos existentes não resultam, necessariamente, na formação de um grupo com objetivos específicos claros. Nesse sentido, convém identificar as interações sociais e a participação comum num dado processo histórico, no âmbito de uma geração, ou seja, sujeitos que pertencem a um mesmo grupo social e compartilham de experiências similares, manifestando, a partir disso, suas tomadas de posiçõos.

Angela de Castro Gomes também nos dá alguns direcionamentos com relação às gerações. Para a autora "uma geração só ganha significado próprio quando remetida a relações com outras gerações" ${ }^{34}$. Como se configurou as relações entre as diferentes gerações no Salão Nacional do Ceará? De que forma cada geração ou grupo de artistas se percebeu e 
construiu sua identidade nesse cenário? E quais foram os meios utilizados por estes grupos para "demarcar" seus espaços já conquistados ou a serem conquistados? De um lado, uma geração mais experiente, vista por muitos como já "consagrada"; do outro, jovens artistas iniciantes, que, em alguns momentos, tinham por referência e buscavam se espelhar na geração tida como consagrada e, em outros momentos, vislumbravam algo novo, novas concepções de arte. É nessa mescla entre distanciamentos e proximidades que o Salão também serviu como palco de disputas e tensões.

Um exemplo ilustrativo dessas tensões se deu na segunda edição do Salão Nacional do Ceará, no qual Estrigas e Nice retiraram seus trabalhos do certame como um protesto contra supostas irregularidades cometidas pelos organizadores do Salão de $1969 .{ }^{35}$ Consultado o catálogo desta edição, verificamos que os premiados foram artistas da nova geração: Tarcísio Félix (Prêmio Raimundo Cela); Marcos Francisco Cavalcante Alcântara ( $1^{\circ}$ Prêmio de Pintura); Descartes Gadelha ( $2^{\circ}$ Prêmio de Pintura); Ruth Bessoudo Courvoisier ( $1^{\circ}$ Prêmio de Gravura); Kleber Ventura ( ${ }^{\circ}$ Prêmio de Gravura); Ruth Werneck Cortês ( $1^{\circ}$ Prêmio de Desenho); Maria Carmen ( $2^{\circ}$ Prêmio de Desenho). Percebemos a ausência, nas premiações, de artistas que fizeram história na época SCAP, como foi o caso de Estrigas e Nice. Estrigas procurou a imprensa para expor sua insatisfação não apenas por não ter sido premiado, mas pela própria escolha da comissão julgadora, presidida, na edição em questão, pelo crítico de arte Roberto Pontual.

$\mathrm{O}$ pintor Estrigas, que retirou seus trabalhos ontem à tarde, declarou a GN que "há possibilidade de se anular o regulamento do Salão não somente através da comprovação das denúncias sobre existência de fraude na escolha da comissão julgadora - denúncias que devem ser examinadas pelas autoridades culturais -, como também pelo desrespeito as normas do Regulamento". (...) O Poeta Otacílio Colares, da Secretaria de Cultura do Estado, disse que os descontentes com a classificação dos premiados do II Salão Nacional de Artes Plásticas do Ceará, têm a disposição o livro de ata da Mostra, no qual os membros da Comissão Julgadora apresentam suas razões, pelos votos dados aos laureados. A inclusão de um ligeiro arrazoado dos membros da Comissão foi feita pela primeira vez num Salão de Arte de Fortaleza por exigência do crítico Roberto Pontual, que presidiu os trabalhos. O renomado crítico nacional explicou sua exigência pelo fato de no sul do país já vir ocorrendo aquela orientação nas exposições de arte. Frisou o poeta Otacílio Colares que o julgamento foi entregue a uma comissão em que figuravam dois críticos escolhidos pelos próprios expositores e intelectuais designados pelo Conselho Estadual de Cultura $^{36}$.

O conflito entre Estrigas e os organizadores do II Salão sinalizou um possível embate entre os artistas e os gestores da cultura, no qual os interesses do Estado não condizem, necessariamente, com os dos artistas. ${ }^{37}$ Enquanto Estrigas se preocupou em defender os seus interesses, pois se sentiu prejudicado pelas decisões da comissão julgadora da mostra, a fala 
de Otacílio Colares foi estritamente institucional, alegando que as escolhas tomadas partiram de críticos estabelecidos e discutidos por intelectuais designados pelo Conselho Estadual de Cultura. Ao que parece, retirar os trabalhos da exposição como manifestação de protesto aos organizadores e julgadores, era uma espécie de modus operandi, haja visto que no Salão de Abril também era comum algumas situações similares ${ }^{38}$.

\section{Algumas Considerações}

Analisamos a inserção dos intelectuais nas instituições oficiais de cultura do Ceará, no período delimitado por este trabalho. Esses intelectuais, que atuaram ativamente nessas instituições, passaram a ter posicionamentos na sociedade, não apenas mais pelo uso da palavra (suas produções e escritos), mas do mesmo modo pelas funções para as quais foram nomeados a desempenhar em tais instituições vinculadas à Secretaria de Cultura do Ceará, sendo que suas atuações nesse meio implicaram na legitimação daqueles que estavam à frente do poder político, como por exemplo, o governador Plácido Aderaldo Castelo. Certamente, Heloisa Juaçaba tivera suas próprias ideias e concepções de arte ao elaborar o projeto de criação da Casa Raimundo e do Salão Nacional do Ceará, mas a execução da referida proposta não deixou de estar "subordinada" às políticas e diretrizes do governo. Norberto Bobbio faz uma distinção entre intelectuais ideólogos e intelectuais expertos. ${ }^{39}$ Para o autor, os ideólogos são aqueles que disseminam princípios, valores e concepções do mundo. Os intelectuais expertos, por sua parte, são aqueles que possuem conhecimentos mais especializados em certa área e por isso, são chamados a desempenhar funções no sistema público, que os políticos em si não são hábeis a cumprir. Nessa perspectiva, a partir do momento em que o Estado passa a intervir em múltiplas estruturas da vida social, entre elas as estruturas culturais, foi crescente a participação dos intelectuais expertos para assumir áreas mais especializadas.

É pertinente pensar que esses intelectuais foram convidados a assumir gestões públicas na área da cultura não somente devido as suas experiências e especialidades nesses setores, mas também por seus círculos de relações, como foi o caso de Heloisa Juaçaba. Do mesmo modo, ocorreu com Otacílio Colares, que devido a sua trajetória como escritor, crítico e jornalista, foi chamado a assumir o Departamento de Difusão Cultural. 


\section{NOTAS:}

${ }^{1}$ NOBRE, Geraldo da Silva. Para a História Cultural do Ceará: O Conselho Estadual de Cultura (1966-1976). Fortaleza: Editora Henriqueta Galeno, 1979, p. 13.

${ }^{2}$ NOBRE, Geraldo da Silva. Para a História Cultural do Ceará: O Conselho Estadual de Cultura (1966-1976). Fortaleza: Editora Henriqueta Galeno, 1979, p. 44-45.

${ }^{3}$ RIBEIRO. Solon. Entrevista. In: SANTOS, Núbia Agustinha Carvalho (org). O inventário de uma obra. Fortaleza: Lumiar Comunicação e Consultoria, 2012, p. 39-40.

${ }^{4}$ Relatório de atividades da Casa Raimundo Cela, 1967.

${ }^{5}$ Catálogo da exposição 28 artistas do acervo do Museu de Arte Contemporânea da Universidade de São Paulo: Fortaleza, Setembro de 1969.

${ }^{6}$ Unitário, 21 de setembro de 1969, p. 13.

${ }^{7}$ Texto de apresentação do Catálogo da $1^{\circ}$ Mostra da Casa Raimundo Cela.

${ }^{8}$ OLIVEIRA, Israel Carvalho de. Entre a intelectualidade e o espírito: domínios da intelectualidade cearense na política cultural (1966 - 1980). Dissertação (Mestrado em História). Universidade Federal do Ceará, 2014, p. 28.

9 BARBALHO. Alexandre Almeida. Relações entre Estado e Cultura no Brasil: A Secretaria de Cultura do Estado do Ceará $(1966$ - 78). Dissertação (Mestrado em Sociologia). Universidade Federal do Ceará, 1997, p. 169.

${ }^{10}$ CARVAlHO, Gilmar de. O voo do pássaro vermelho. In: SANTOS, Núbia Agustinha Carvalho (org). $O$ inventário de uma obra. Fortaleza: Lumiar Comunicação e Consultoria, 2012, p. 17-18.

${ }^{11}$ BARBALHO. Alexandre Almeida. Relações entre Estado e Cultura no Brasil: A Secretaria de Cultura do Estado do Ceará (1966 - 78). Dissertação (Mestrado em Sociologia). Universidade Federal do Ceará, 1997, p. 175.

${ }^{12}$ SIRINELLI, Jean François. As elites culturais. In: RIOUX, Jean-Pierre, SIRINELLI, Jean-François. Para uma história cultural. Lisboa: Editorial Estampa, 1998, pp. 261-272.

${ }^{13}$ GUIMARÃES, Dodora. Heloysa Juaçaba. A pintora, a colecionadora, a animadora cultural. In: SANTOS, Núbia Agustinha Carvalho (org). O inventário de uma obra. Fortaleza: Lumiar Comunicação e Consultoria, 2012, p. 85.

${ }^{14}$ Gazeta de Notícias, 17 de setembro de 1967, p.4.

${ }^{15}$ ORTIZ. Renato. Cultura Brasileira e identidade nacional. São Paulo: Brasiliense, 2012, p. 84-85.

${ }^{16}$ Catálogo do 10 Salão Nacional de Artes Plásticas do Ceará, Setembro de 1967.

${ }^{17}$ Unitário. 30 expositores no II Salão dos Novos, 04 de outubro de 1969, p. 4.

${ }^{18}$ Correio do Ceará. Exposição de arte infantil será aberta domingo, 06 de outubro de 1969, p. 2.

${ }^{19}$ Gazeta de Notícias. Um Salão de Arte fotográfica, 09 de dezembro de 1973, p. 7.

${ }^{20}$ Ver: SILVA, Anderson de Sousa. O Salão de Abril em dois momentos: Sociedade Cearense de Artes Plásticas (SCAP) e Prefeitura Municipal de Fortaleza (1944-1970). Dissertação (Mestrado em História). Universidade Federal do Ceará. Fortaleza, 2015.

${ }^{21}$ Tribuna do Ceará. Governador na abertura do Salão Nacional de Artes Plásticas, 13 de setembro de 1973, p. 4.

${ }^{22}$ URFALINO, Philippe. A História da política cultural. In: RIOUX, Jean-Pierre, SIRINELLI, Jean-François. Para uma história cultural. Lisboa: Editorial Estampa, 1998, p. 299.

${ }^{23}$ OLIVEIRA, Israel Carvalho de. Entre a intelectualidade e o espírito: domínios da intelectualidade cearense na política cultural (1966 - 1980). Dissertação (Mestrado em História). Universidade Federal do Ceará, 2014, p. 15.

${ }^{24}$ Unitário. Exposição na Galeria Pedro Jorge reunirá grandes pintores, 03 de setembro de 1967, p. 11.

${ }^{25}$ Gazeta de Notícias - Coluna Balaio/Artes plásticas. Nearco na Galeria do Ideal, 22 de dezembro de 1969, p. 5 .

${ }^{26}$ Gazeta de Notícias - Coluna Balaio/Artes plásticas. Recanto de Ouro Preto é o programa de hoje, 16 de julho de 1971, p. 7.

${ }^{27}$ Catálogo do $4^{\circ}$ edição do Salão Nacional de Artes Plásticas do Ceará, 1973.

${ }^{28}$ LUZ. Angela Ancora da. Uma breve História dos Salóes de Artes: Da Europa ao Brasil. Rio de Janeiro: Caligrama, 2005, p. 140.

${ }^{29}$ FREIRE, Cristina. Arte Conceitual. Rio de Janeiro: Zahar, 2006, p. 08-09.

${ }^{30}$ REIS, Paulo. Arte de vanguarda no Brasil: os anos 60. Rio de Janeiro: Jorge Zahar, 2006, p. 45.

${ }^{31}$ OLIVEIRA, Israel Carvalho de. Entre a intelectualidade e o espírito: domínios da intelectualidade cearense na política cultural (1966 - 1980). Dissertação (Mestrado em História). Universidade Federal do Ceará, 2014, p. 20. 


\footnotetext{
${ }^{32}$ CARVALHO, Gilmar de. O voo do pássaro vermelho. In: SANTOS, Núbia Agustinha Carvalho (org). $O$ inventário de uma obra. Fortaleza: Lumiar Comunicação e Consultoria, 2012, p. 16-17.

${ }^{33}$ MANNHEIM, Karl. O problema sociológico das gerações. In FORACCHI, M.M. (Org.), Mannheim, Coleção Grandes Cientistas Sociais, 25. São Paulo: Ed. Ática, 1982, p. 71.

${ }^{34}$ GOMES, Angela de Castro. História e historiadores. Rio de Janeiro: Editora Fundação Getúlio Vargas, 1996, p. 41 .

35 Gazeta de Notícias - Coluna Balaio/Artes plásticas. Artistas retiram seus trabalhos do II Salão, 04 de novembro de 1969.

${ }^{36}$ Gazeta de Notícias - Coluna Balaio/Artes plásticas. Artistas retiram seus trabalhos do II Salão, 04 de novembro de 1969.

37 BECKER. Howard S. Mundos da Arte. Lisboa: Livros Horizonte, 2010, p. 152.

${ }^{38}$ ESTRIGAS, Nilo de Firmeza. O Salão de Abril: 1943 - 2009. $2^{\circ}$ Edição. Fortaleza: La Barca Editora, 2009, p. 84

${ }^{39}$ BOBBIO, Norberto. Os intelectuais e o poder: dúvidas e opções dos homens de cultura na sociedade contemporânea. São Paulo: Editora da Universidade Estadual Paulista, 1997, p. 71-73.
}

\section{Referências Bibliográficas :}

BARBALHO. Alexandre Almeida. Relações entre Estado e Cultura no Brasil: A Secretaria de Cultura do Estado do Ceará (1966 - 78). Dissertação (Mestrado em Sociologia). Universidade Federal do Ceará, 1997.

BECKER, Howard. Mundos da Arte. Lisboa: Livros Horizonte, 2010.

BOBBIO, Norberto. Os intelectuais e o poder: dúvidas e opções dos homens de cultura na sociedade contemporânea. São Paulo: Editora da Universidade Estadual Paulista, 1997.

CARVALHO, Gilmar de. O voo do pássaro vermelho. In: SANTOS, Núbia Agustinha (org). O inventário de uma obra. Fortaleza: Lumiar Comunicação e Consultoria, 2012.

ESTRIGAS, Nilo de Firmeza. O Salão de Abril: 1943 - 2009. $2^{\circ}$ Edição. Fortaleza: La Barca Editora, 2009.

FREIRE, Cristina. Arte Conceitual. Rio de Janeiro: Zahar, 2006.

GOMES, Angela de Castro. História e historiadores. Rio de Janeiro: Editora Fundação Getúlio Vargas, 1996.

GUIMARÃES, Dodora. Heloysa Juaçaba. A pintora, a colecionadora, a animadora cultural. In: SANTOS, Núbia Agustinha Carvalho (org). O inventário de uma obra. Fortaleza: Lumiar Comunicação e Consultoria, 2012.

NOBRE, Geraldo da Silva. Para a História Cultural do Ceará: O Conselho Estadual de Cultura (1966-1976). Fortaleza: Editora Henriqueta Galeno, 1979.

OLIVEIRA, Israel Carvalho de. Entre a intelectualidade $e$ o espírito: domínios da intelectualidade cearense na política cultural (1966 - 1980). Dissertação (Mestrado em História). Universidade Federal do Ceará, 2014.

ORTIZ. Renato. Cultura Brasileira e identidade nacional. São Paulo: Brasiliense, 2012. 
RIBEIRO. Solon. Entrevista. In: SANTOS, Núbia Agustinha Carvalho (org). O inventário de uma obra. Fortaleza: Lumiar Comunicação e Consultoria, 2012.

REIS, Paulo. Arte de vanguarda no Brasil: os anos 60. Rio de Janeiro: Jorge Zahar, 2006.

SILVA, Anderson de Sousa. O Salão de Abril em dois momentos: Sociedade Cearense de Artes Plásticas (SCAP) e Prefeitura Municipal de Fortaleza (1944-1970). Dissertação (Mestrado em História). Universidade Federal do Ceará. Fortaleza, 2015.

SIRINELLI, Jean François. As elites culturais. In: RIOUX, Jean-Pierre, SIRINELLI, JeanFrançois. Para uma história cultural. Lisboa: Editorial Estampa, 1998.

URFALINO, Philippe. A História da política cultural. In: RIOUX, Jean-Pierre, SIRINELLI, Jean-François. Para uma história cultural. Lisboa: Editorial Estampa, 1998. 